\title{
PENGARUH BUDAYA ORGANISASI DAN GAYA KEPEMIMPINAN TERHADAP KINERJA GURU DENGAN LINGKUNGAN KERJA DAN KEPUASAN KERJA SEBAGAI VARIBEL INTERVENING PADA GURU SMA DI KECAMATAN DEWANTRAA KABUPATEN ACEH UTARA
}

\author{
Nurlaili, Apridar, Aiyub \\ PPIM Universitas Malikussaleh, Lhokseumawe
}

\begin{abstract}
This study aims to determine the effect of organizational culture and leadership style on teacher performance with work environment and job satisfaction as an intervening variable. The data used are primary data by distributing questionnaires to 140 respondents, namely teachers who teach at Senior High Schools in Dewantara District, North Aceh Regency. The method used to analyze the data is Structural Equation Modeling (SEM). The results of the study found that the organizational culture and work environment had a positive and significant effect on the work environment and job satisfaction of senior high school teachers in Dewantara District, North Aceh Regency. Furthermore, found organizational culture, leadership style, work environment and job satisfaction have a positive and significant effect on the performance of high school teachers in Dewantara District, North Aceh Regency. Furthermore, it was found that work environment variables and job satisfaction mediate fully the influence of organizational culture and leadership style on the performance of high school teachers in Dewantara District, North Aceh Regency. Based on the results of these studies it is expected that the leaders or principals in Dewantara Subdistrict, North Aceh Regency be able to give attention and priority in institutionalizing organizational culture and creating a conducive work environment to improve job satisfaction and teacher performance.
\end{abstract}

Keywords: organizational culture, leadership style, work environment, job satisfaction and teacher performance

\section{PENDAHULUAN}

Keberhasilan guru dalam kegiatan belajar mengajar ditentukan oleh kinerja guru sebagai tenaga pendidik. Jika kinerja guru baik maka hasil proses belajar mengajar akan baik pula, sehingga berdampak secara signifikan terhadap mutu lulusan yang dihasilkan dalam sebuah instansi pendidikan. Kinerja guru penting dalam mencapai tujuan pembelajaran yang optimal. Kinerja (performance) adalah keluaran yang dihasilkan oleh individu-individu pada suatu pekerjaan atau suatu profesi tertentu. Kinerja yang sering juga disebut sebagai prestasi kerja adalah hasil kerja secara kuantitas dan kualitas yang dicapai seseorang dalam melaksanakan tugas sesuai tanggung jawab yang diberikan pada waktu tertentu. Kinerja merupakan gambaran pencapaian pelaksanaan suatu kegiatan/program/ kebijaksanaan dalam mewujudkan sasaran, tujuan, misi, visi organisasi (Bastian, 2014). 
Terdapat banyak faktor yang mempengaruhi kinerja, misalnya berdasarkan pendapat Taurisa dan Ratnawati (2012) mengatakan bahwa secara umum kinerja pegawai dipengaruhi oleh dua faktor yaitu faktor internal (kepuasan kerja dan komitmen organisasional) dan faktor eksternal (kepemimpinan, keamanan, lingkungan kerja, keselamatan kerja dan budaya organisasi). Secara empirikal terdapat beberapa penelitian terdahulu yang meneliti tentang pengaruh kepuasan kerja dengan kinerja guru, misalnya penelitian Rizqi, Ushada dan Supartono (2015), Arifin (2012), Budiawan (2012), Christologus dan Indriyani (2010), Subekti (2008), dan Hakim (2013), hasil penelitian mereka menemukan bahwa kepuasan kerja berpengaruh signifikan terhadap kinerja karyawan.

Faktor lain yang mempengaruhi kinerja adalah lingkungan kerja. Lingkungan kerja adalah kekuatan yang mendorong semangat yang ada di dalam maupun diluar dirinya baik itu yang berupa reward maupun funishment. Herberg dalam Luthans (2003). Secara empirikal terdapat beberapa penelitian terdahulu yang telah dilakukan untuk mencari hubungan antra lingkungan kerja dengan kinerja, misalnya penelitian Dhermawan et al. (2012), Dienillah (2018), Elfita, Zulhaini, dan Mailani (2019), Eliyanto (2018), Yumaroh dan Andriani (2017) dimana penelitian mereka menemukan bahwa lingkungan kerja berpengaruh terhadap kinerja. Penelitian lainnya adalah penelitian Dhermawan, Sudibya, Adnyana dan Mudiartha (2012), Wahyunardi dan Nurjaman (2018), yang menemukan bahwa budaya organisasi dan lingkungan kerja berpengaruh signifikan terhadap kepuasan kerja dan kinerja pegawai.

Di samping itu faktor lainnya yang mempengaruhi kinerja adalah gaya kepemimpinan. Gaya kepemimpinan dalam organisasi sangat diperlukan untuk mengembangkan lingkungan kerja yang kondusif dan membangun budaya organisasi bagi karyawan sehingga diharapkan akan menghasilkan kinerja yang tinggi (Darwito,2008). Menurut Judge dan Piccolo (2004) mengatakan bahwa terdapat hubungan positif antara kepemimpinan transformasional dengan sikap, perilaku, dan kinerja pegawai. Para ahli lainnya mengemukakan bahwa gaya kepemimpinan merupakan faktor penting yang dapat meningkatkan kinerja (Bass et al, 2003). Secara empirikal terdapat beberapa penelitian terdahulu yang meneliti tentang pengaruh gaya kepemimpinan terhadap kepuasan kerja, misalnya penelitian Suastika dan Putra (2012), Kilapong (2013), Suyuthi, Hamzah dan Payangan (2012), Anggraeni dan Santosa (2013), Brahmasari dan Suprayetno (2008), Lipu, Alam dan Umar (2013), Ricky (2009), Mulyanto dan Widayati (2009), Posuma (2013), Sari, Muis dan Hamid (2012) yang menemukan bahwa gaya kepemimpinan, berpengaruh signifikan terhadap kinerja karyawan. Penelitian lainnya adalah penelitian Suastika dan Putra (2012) Kilapong (2013) Suyuthi, Hamzah dan Payangan (2012) Anggraeni dan Santosa (2013), penelitian mereka menemukan bahwa gaya kepemimpinan berpengaruh positif terhadap kepuasan kerja karyawan.

Faktor lainnya yang mempengaruhi kinerja pegawai adalah budaya organisasi. Budaya Organisasi adalah sistem makna, nilai-nilai dan kepercayaan yang dianut bersama dalam suatu organisasi yang menjadi rujukan untuk bertindak dan membedakan organisasi satu dengan organisasi lainnya (Mas'ud, 2004). Secara imperikal telah banyak penelitian yang dilaksanakan peneliti terdahulu untuk mengetahui pengaruh budaya organisasi terhadap lingkungan kerja misalnya penelitian Kurniasari (2013) dan valizadeh, Ghahremani (2012) dan Andre, Sjovold, Rannestad, dan Rigdal (2014) yang menyimpulkan bahwa budaya organisasi sangat penting dalam mempengaruhi lingkungan kerja. 
Penelitian Ketut (2010), Brahmasari dan Suprayetno (2008), Wahyunardi dan Nurjaman (2018) yang menemukan bahwa budaya organisasi dan lingkungan kerja berpengaruh signifikan terhadap kepuasan kerja dan kinerja pegawai. Penelitian lainnya adalah penelitian Ketut (2010), Brahmasari dan Suprayetno (2008), Wahyunardi dan Nurjaman (2018) yang menemukan bahwa lingkungan kerja berpengaruh signifikan terhadap kepuasan kerja dan kinerja pegawai. Hasil penelitian lain adalah Patulak et.al (2014), Putriana (2015), Kusworo et.al (2015), Shahzad (2013) dan Hakim (2015), Brahmasari dan Suprayetno (2008) dimana mereka menemukan bahwa budaya organisasi berpengaruh positif dan signifikan terhadap kinerja perusahaan.

\section{STUDIKEPUSTAKAAN BUDAYA ORGANISASI}

Budaya sekolah adalah nilai-nilai dominan yang didukung oleh sekolah atau falsafah yang menuntun kebijakan sekolah terhadap semua unsur dan komponen sekolah termasuk stakeholders pendidikan, seperti cara melaksanakan pekerjaan di sekolah serta asumsi atau kepercayaan da sar yang dianut oleh personil sekolah. Budaya sekolah merujuk pada suatu sistem nilai, kepercayaan dan norma-norma yang diterima secara bersama, serta dilaksanakan dengan penuh kesadaran sebagai perilaku alami, yang dibentuk oleh lingkungan yang menciptakan pemahaman yang sama diantara seluruh unsur dan personil sekolah baik itu kepala sekolah, guru, staf, siswa dan jika perlu membentuk opini masyarakat yang sama dengan sekolah. (Akhmad Sudrajat, 2010).

Sudrajat (2010) bahwa budaya organisasi adalah nilai-nilai dominan yang didukung oleh organisasi atau falsafah yang menuntun kebijakan oragnsiasi terhadap semua unsur dan komponen organisasi termasuk stakeholders pendidikan. Budaya organisasi yang baik, yang dipahami dan diamalkan dalam seluruh tindakan personil disekolah akan memberikan daya dorong yang kuat untuk menciptakan kondusifitas dalam segala bidang di suatu organisasi. Hasil penelitian ini juga sejalan dengan pendapat Ogboma dan Lloyd (2000), yang mengatakan bahwa budaya organisasi akan menciptakan suasana dan lingungan organisasi yang lebih baik dan peningkatan kinerja yang dapat menghasilkan keunggulan kompetitif bagi organisasi tersebut.

\section{GAYA KEPEMIMPINAN}

Menurut Wahyudi, (2012: 120) kepemimpinan dapat diartikan sebagai kemampuan seseorang dalam menggerakkan, mengarahkan sekaligus mempengaruhi pola pikir, cara kerja setiap anggota agar bersikap mandiri dalam bekerja untuk kepentingan percepatan pencapaian tujuan yang telah ditetapkan. Gaya kepemimpinan mengandung pengertian sebagai suatu perwujudan tingkah laku dari seorang pemimpin yang menyangkut kemampuannya dalam memimpin bawahannya. Menurut (Miftah Thoha, 2015: 49) gaya kepemimpinan merupakan "norma perilaku yang digunakan oleh seorang pada saat orang tersebut mempengaruhi orang lain.” Gaya kepemimpinan kepala sekolah yang baik serta didukung oleh pendayagunaan peran dan fungsi kepemimpinannya, dapat menciptakan lingkungan kerja yang kondusif. 


\section{LINGKUNGAN KERJA}

Lingkungan kerja adalah kekuatan yang mendorong semangat yang ada didalam maupun diluar dirinya baik itu yang berupa reward maupun fanishment sehingga Herberg dalam Luthans (2003) menyatakan bahwa pada manusia terdapat enam faktor pemuas: 1) prestasi kerja yang diraih (achivement), 2) Pengakuan orang lain (recognition), tanggung jawab (responsibility), 4) peluang untuk maju (advancement), 5) kepuasan kerja itu sendiri (the workitself), 6) dan pengembangan karir ( the possibility of growth). Sedangkan faktor lingkungan kerja meliput: 1) Kondisi kerja, 2) Keamanan dan keselamatan kerja, 3) Kondisi tempat kerja, 4) Status, 5) Prosedur perusahaan, 6) Mutu dari supervise tekhnis dari hubungan antara teman sejawat, atasan dan bawahan.

\section{KEPUASAN KERJA}

Menurut Mathis dan Jackson (2011), kepuasan kerja merupakan keadaan emosi yang positif dari mengevaluasi pengalaman kerja seseorang. Sedangkan menurut Gibson, et al. (2000), kepuasan kerja (Job Satisfaction) dapat juga disebut dengan istilah Employee Morale Contentment, atau Happiness. Namun pada umumnya istilah kepuasan kerja yang sering digunakan. Selanjutnya Gibson, et al. (2000), menyatakan bahwa "Kepuasan kerja adalah tentang perilaku para pekerja tentang pekerjaan mereka. Yang dihasilkan dari persepsi tentang pekerjaan-pekerjaannya".

Kepuasan kerja adalah keadaan emosional yang menyenangkan atau tidak menyenangkan dimana para pekerja memandang pekerjaannya. Kepuasan kerja merupakan cerminan dari perasaan pekerja terhadap pekerjaannya. Hal ini tampak dalam sikap positif pekerja terhadap pekerjaan yang dihadapi dan lingkungannya. Sebaliknya, pekerja yang tidak puas akan bersikap negatif terhadap pekerjaan dengan bentuk yang berbeda-beda satu dengan yang lainnya (Nugroho \& Kunartinah, 2012).

\section{METODE PENELITIAN}

Lokasi penelitian ini adalah pada SMA di Kecamatan Dewantara Kabupaten Aceh Utara. Sedangkan yang menjadi objek penelitian adalah guru yang mengajar pada SMA di Kecamatan Dewantara. Populasi dalam penelitian ini adalah seluruh guru SMA di Kecamatan Dewantara Kabupaten Aceh Utara yang berjumlah 152 orang. Jumalah sampel dalam penelitian ini sebanyak 140 orang responden sesuai dengan persyaratan SEM. Teknik pengambilan sampel dilakukan dengan menggunakan teknik probability sampling, dengan tidak membedakan guru Pegawai Negeri Sipil (PNS) maupun guru honorer. Metode pengumpulan data yang digunakan dalam penelitian ini yaitu instrumen kuesioner dengan menggunakan skala 1-5 (likert). Teknik analisis data yang digunakan pada penelitian ini adalah dengan menggunakan SEM (Structural Equation Modeling) dengan program AMOS (Analysis of Moment Structure).

Model mediasi pertama sekali diperkenalkan oleh Baron dan Kenny (1986) yang selanjutnya dikembangkan oleh Preacher dan Hayes (2010), yang menjelaskan tentang prosedur analisis variabel mediator secara sederhana melalui regresi. Menurut Preacher dan Hayes (2010) suatu variabel disebut variabel intervening jika variabel tersebut ikut mempengaruhi hubungan antara variabel independen dengan variabel dependen. Pengujian hipotesis mediasi dapat dilakukan dengan prosedur uji Sobel (Sobel Test). 


\section{HASIL DAN PEMBAHASAN}

Hasil analisis data terhadap full model penelitian diperlihatkan dalam Gambar 1.

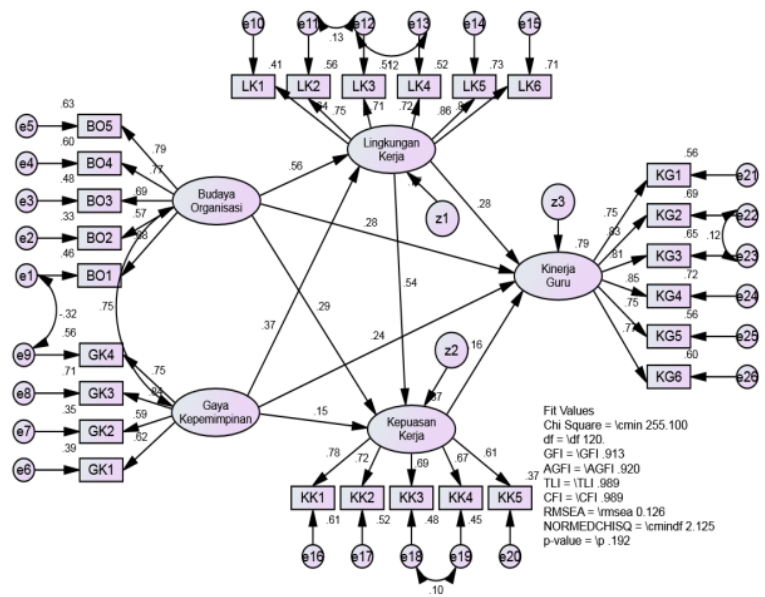

Gambar 1 Full Model Penelitian Setelah Modifikasi

Untuk mengetahui pengaruh, arah pengaruh dan signifikansi pengaruh variabel eksogen terhadap variabel endogen maka dilakukan analisis estimasi nilai parameter. Nilai koefisien yang digunakan adalah nilai estimate standardized regression weights seperti yang diperlihatkan dalam Tabel 1.

Tabel 1 Estimate Standardized Regression Weights

\begin{tabular}{cccccccc}
\hline & & & \multicolumn{2}{c}{ Estimate } & S.E. & C.R. & P \\
& & & Unstandard & Standard & & & \\
\hline Lingkungan_Kerja & $<---$ & Budaya_Organisasi & 0.440 & 0.562 & 0.104 & 4.228 & $* * *$ \\
Lingkungan_Kerja & $<---$ & Gaya_Kepemimpinan & 0.375 & 0.371 & 0.119 & 3.145 & 0.002 \\
Kepuasan_Kerja & $<---$ & Budaya_Organisasi & 0.212 & 0.291 & 0.106 & 2.604 & 0.045 \\
Kepuasan_Kerja & $<---$ & Gaya_Kepemimpinan & 0.143 & 0.152 & 0.113 & 2.268 & 0.048 \\
Kinerja_Guru & $<---$ & Budaya_Organisasi & 0.267 & 0.277 & 0.146 & 2.823 & 0.038 \\
Kinerja_Guru & $<---$ & Gaya_Kepemimpinan & 0.300 & 0.241 & 0.129 & 3.047 & 0.019 \\
Kinerja_Guru & $<---$ & Lingkungan_Kerja & 0.340 & 0.276 & 0.136 & 3.145 & 0.002 \\
Kinerja_Guru & $<---$ & Kepuasan_Kerja & 0.211 & 0.160 & 0.206 & 2.402 & 0.042 \\
Kepuasan_Kerja & $<---$ & Lingkungan_Kerja & 0.505 & 0.543 & 0.156 & 4.237 & 0.001 \\
\hline
\end{tabular}

ntuk mengetahui apakah disiplin kerja mediasi hubungan antara kepemimpinan, gaya kepemimpinan dan komunikasi dengan produktivitas karyawan, dilakukan uji efek mediasi dengan menggunakan kriteria atau tahapan yang dilakukan oleh Baron \& Kenny (1986). Berdasarkan hasil perhitungan efek mediasi lingkungan kerja memediasi secara penuh (full mediation) hubungan budaya organisasi dengan kinerja guru SMA di Kecamatan Dewantara. Kepuasan kerja memediasi secara penuh (full mediation) hubungan budaya organisasi dengan kinerja guru SMA di Kecamatan Dewantara. Lingkungan kerja memediasi secara penuh (full mediation) hubungan gaya kepemimpinan dengan kinerja guru SMA di Kecamatan Dewantara, dan kepuasan kerja memediasi secara penuh (full mediation) hubungan gaya kepemimpinan dengan kinerja guru SMA di Kecamatan Dewantara. 


\section{PENGARUH ORGANISASI TERHADAP LINGKUNGAN KERJA}

Berdasarkan data dapat dijelaskan bahwa pengaruh budaya organisasi terhadap lingkungan kerja sebesar 0.562 atau $56.2 \%$ dan nilai probabilitas sebesar 0,000 (***) yang jauh lebih kecil dari 0,05 (5\%). Hasil ini memberi arti bahwa apabila budaya organisasi meningkat sebesar 1 pada ukuran standar deviasi, maka lingkungan kerja akan meneingkat sebesar 0.562 pada ukuran standar deviasi. Secara imperikal hasil penelitian ini sejalan dan mendukung hasil penelitian yang dilaksanakan oleh Kurniasari (2013), Valizadeh \& Ghahremani (2012), Andre, Sjovold, Rannestad, dan Rigdal (2014).

\section{PENGARUH GAYA KEPEMIMPINAN TERHADAP LINGKUNGAN KERJA}

Berdasarkan data yang dapat dijelaskan bahwa pengaruh gaya kepemimpinan terhadap lingkungan kerja sebesar 0.371 atau 37.1\% dengan probabilitas sebesar 0,002 yang lebih kecil dari 0,05. Hasil ini memberi makna bahwa apabila gaya kepemimpinan kepala sekolah yang ada di lingkungan SMA di Kecamatan Dewantara berjalan sesuai dengan harapan guru misalnya kepala sekolah mampu memberitahukan atau berkomunikasi dengan baik, mampu menjual atau mempromosi ide-ide para guru, ikut berpartisipasi dalam setiap kegiatan yang dilakukan oleh guru di sekolah dan dapat mendelegasikan tugas kepada bawahan dengan baik dan jelas, maka akan terjadi peningkatan dan dorongan kepada para guru untuk menciptakan suasana kerja dan lingkungan kerja yang lebih kondusif dan nyaman. Hasil penelitian ini juga sejalan dengan apa yang dikatakan oleh Thoha (2015), Danthi (2017), Norlina, Rohani, Mazlina, dan Nazri (2015) yang menemukan bahwa gaya kepemimpinan berpengaruh signifikan terhadap qualitas budaya kerja dan lingkungan kerja.

\section{PENGARUH BUDAYA ORGANISASI TERHADAP KEPUASAN KERJA}

Berdasarkan data yang ditampilkan dapat dijelaskan pengaruh budaya organisasi terhadap kepuasan kerja sebesar 0.291 atau 29.1\% dengan nilai probabilitas 0.045 yang jauh lebih kecil dari 0,05. Hasil ini memberi arti bahwa apabila budaya organisasi meningkat sebesar 1 pada ukuran standar deviasi, maka akan meningkatkan kepuasan kerja guru di SMA Kecamatan Dewantara sebesar 0,291 pada ukuran standar deviasi. Sistem makna dan nilai-nilai yang dianut di lingkungan SMA Dewantara yang meliputi semua kegiatan yang dijalankan berorientasi pada prosesdan guru, bersifat partisipasif, menganut sistem yang terbuka dan bersifat normatif telah mampu meningkat kepuasan kerja para guru di lingkungan SMA Kecamatan Dewantara. Secara empirikal pula, telah banyak penelitian yang dilakukan untuk mencari pengaruh budaya organisasi dengan kepuasan kerja misal penlitian Ketut (2010), Brahmasari dan Suprayetno (2008), Wahyunardi dan Nurjaman (2018) yang menemukan bahwa budaya organisasi dan lingkungan kerja berpengaruh signifikan terhadap kepuasan kerja dan kinerja pegawai.

\section{PENGARUH GAYA KEPEMIMPINAN TERHADAP KEPUASAN KERJA}

Berdasarkan data dapat dijelaskan bahwa pengaruh kepemimpinan terhadap kepuasan kerja adalah sebesar 0.152 atau $15.2 \%$ dengan probabilitas sebesar 0,045 yang jauh lebih kecil dari 0,05\%. Hasil ini memberi arti bahwa apabila gaya kepemimpinan meningkat 1 pada ukuran standar deviasi dalam arti kata gaya kepemimpinan yang diperankan oleh pimpinan pada SMA di Kecamatan 
Dewantara berjalan dengan baik dan sesuai dengan harapan dari para guru maka akan meningkatkan kepuasan kerja guru sebesar 0.152 pada ukuran standar deviasi. Secara empirikal hasil penelitian ini sesuai dan mendukung hasil penelitian yang dilakukan oleh Suastika dan Putra (2012), Kilapong (2013), Suyuthi, Hamzah dan Payangan (2012, Anggraeni dan Santosa (2013).

\section{PENGARUH BUDAYA ORGANISASI TERHADAP KINERJA GURU}

Berdasarkan data dapat dijelaskan pengaruh budaya organisasi terhadap kinerja guru di SMA Kecamatan Dewantara Kabupaten Aceh Utara sebesar 0.277 atau 27.7\% dengan nilai probabilitas sebesar 0,038 yang jauh lebih kecil dari 0.05. Hasil ini memberi arti bahwa apabila budaya organisasi meningkat 1 pada ukuran standar deviasi maka akan meningkatkan kinerja guru di SMA Dewantara Kabupaten Aceh Utara. Secara emperikal hasil penelitian ini mendukung dan memperkuat beberapa hasil penelitian sebelumnya misalnya Patulak et.al (2014), Putriana (2015), Kusworo et.al (2015), Shahzad (2013) dan Hakim (2015).

\section{PENGARUH GAYA KEPEMIMPINAN TERHADAP KINERJA GURU}

Berdasarkan analisis data dapat dijelaskan pengaruh gaya kepemimpinan terhadap kinerja guru SMA di Kecamatan Dewantara Kabupaten Aceh Utara sebesar 0.241 atau 24.1\% dengan nilai probabilitas sebesar 0,019 yang jauh lebih kecil dari 5\%. Hasil ini memberi makna bahwa apabila gaya kepemimpinan meningkat 1 pada ukuran standar deviasi maka kinerja guru akan meningkat sebesar 0.241 pada ukuran standar deviasi. Secara empirikal pula hasil penelitian ini juga mendukung dan sejalan dengan hasil penelitian Lipu, Alam dan Umar (2013), Ricky (2009), Mulyanto dan Widayati (2009), Posuma (2013),Sari, Muis dan Hamid (2012) yang menemukan bahwa gaya kepemimpinan, berpengaruh signifikan terhadap kinerja karyawan.

\section{PENGARUH LINGKUNGAN KERJA TERHADAP KINERJA GURU}

Berdasarkan hasil analisis data dapat dijelaskan bahwa pengaruh lingkungan kerja terhadap kinerja guru adalah sebesar 0.276 atau 27,6\% dengan probabilitas sebesar 0,002 yang jauh lebih kecil dari $0,05 \%$. Hasil ini memberi arti bahwa apabila lingkungan kerja meningkat 1 pada ukuran standar deviasi, dalam arti kata lingkungan kerja meningkat ke arah yang lebih kondusif pada SMA di Kecamatan Dewantara maka akan meningkatkan kinerja guru sebesar 0.276 pada ukuran standar deviasi. Hasil penelitian sejalan dan mendukung beberapa hasil penelitian terdahulu misalnya penelitian Dhermawan et al. (2012), Dienillah (2018), Elfita, Zulhaini, dan Mailani (2019), Eliyanto (2018), Yumaroh dan Andriani (2017) dimana penelitian mereka menermukan lingkungan kerja berpengaruh terhadap kinerja guru/pegawai.

\section{PENGARUHKEPUASAN KERJA TERHADAP KINERJA GURU}

Berdasarkan analisis data dapat dijelaskan bahwa pengaruh kepuasan kerja terhadap kinerja guru SMA di Kecamatan Dewantara adalah sebesar 0.160 atau 16.0\% dengan probabilitas sebesar 0,042 yang jauh lebih kecil dari 0,05\%. Hasil ini memberi arti bahwa apabila kepuasan kerja meningkat 1 pada ukuran standar deviasi, maka akan meningkatkan kinerja guru SMA di Kecamatan Dewantara sebesar 0.160 pada ukuran standar deviasi. Secara empirikal hasil penelitian ini sejalan dengan penelitian Rizqi, Ushada dan Supartono (2015), Arifin (2012), Budiawan (2012), Christologus dan Indriyani (2010), 
Subekti (2008), Hakim (2013), hasil penelitian menunjukkan bahwa kepuasan kerja berpengaruh signifikan terhadap kinerja karyawan.

\section{PENGARUH LINGKUNGAN KERJA TERHADAP KEPUASAN KERJA}

Berdasarkan analsisi data dapat dijelaskan bahwa pengaruh lingkungan kerja terhadap kepuasan kerja guru SMA di Kecamatan Dewantara adalah sebesar 0.543 atau 54,3\% dengan probabilitas sebesar 0,001 yang jauh lebih kecil dari $0,05 \%$. Hasil ini memberi arti bahwa apabila lingkungan kerja meningkat 1 pada ukuran standar deviasi, maka akan meningkatkan kepuasan kerja guru di SMA di Kecamatan Dewantara sebesar 0.543 pada ukuran standar deviasi. Secara emperikal pula, hasil penelitian ini sejalan dan mendukung hasil penelitian terdahulu misalnya penelitian Dhermawan, Sudibya, Adnyana dan Mudiartha. (2012) yang menemukan bahwa lingkungan kerja berpengaruh terhadap kepuasan kerja dan kinerja pegawai di lingkungan Kantor Dinas Pekerjaan Umum Provinsi Bali. Penelitian ini juga sesuai dan sejalan dengan hasil penelitian Wahyunardi dan Nurjaman (2018) yang menemukan bahwa budaya organisasi dan lingkungan kerja berpengaruh signifikan terhadap kepuasan kerja dan kinerja pegawai PT. PLN Majalaya Jawa Barat.

\section{PENGARUH BUDAYA ORGANISASI TERHADAP KINERJA GURU MELALUI LINGKUNGAN KERJA}

Berdasarkan hasil perhitungan efek mediasi pengaruh budaya organisasi terhadap kinerja guru melalui lingkungan kerja pada SMA Kecamatan Dewantara Kabupaten Aceh Utara dapat dijelaskan bahwa lingkungan kerja memediasi secara penuh (full mediation) hubungan budaya organisasi dengan kinerja guru SMA di Kecamatan Dewantara Kabupaten Aceh Utara. Hasil ini memberi makna bahwa budaya organisasi akan berpengaruh terhadap kinerja guru SMA di Kecamatan Dewantara harus melalui upaya terciptanya lingkungan kerja yang kondusif sesuai dengan indikator lingkungan kerja yang diharapkan oleh para guru di SMA di Kecamatan Dewantara. Dengan kata lain bahwa pimpinan pada SMA di Kecamatan Dewantara harus fokus pada upaya menciptakan lingkungan kerja yang kondusif untuk meningkatkan peran atau fungsi budaya organisasi dalam meningkatkan kinerja guru SMA di lingkungan Kecamatan Dewantara Aceh Utara. Kajian empirikal dalam bidang ini berdasarkan penelusuran karya ilmiah baik secara online maupun secara ofline (bahan bercetak) yang dilakukan oleh peneliti tidak ditemukan adanya artikel atau jurnal yang menempatkan lingkungan kerja sebagai variabel mediasi antara gaya kepemimpinan dan budaya organisasi terhadap kinerja pegawai atau guru. Oleh karena itu penulis tidak dapat membandingkan hasil penelitian ini dengan penelitian lainnya. Namun demikian penelitian ini diharapkan menjadi sesuatu yang baru dalam model efek mediasi dan menjadikan manfaat dalam menambah referensi ilmiah dalam bidang terkait. 


\section{PENGARUH BUDAYA ORGANISASI TERHADAP KINERJA GURU MELALUI KEPUASAN KERJA}

Berdasarkan hasil perhitungan efek mediasi tentang pengaruh budaya organisasi terhadap kinerja guru SMA di Kecamatan Dewantara Kabupaten Aceh Utara melalui kepuasan kerja sebagai variabel intervening, dapat dijelaskan bahwa kepuasan kerja memediasi secara penuh (full mediation) hubungan budaya organisasi dengan kinerja guru SMA di Kecamatan Dewantara Kabupaten Aceh Utara. Hasil ini memberi makna bahwa budaya organisasi akan berpengaruh terhadap kinerja guru SMA di Kecamatan Dewantara harus melalui upaya peningkatan kepuasan kerja. Dengan kata lain bahwa apabila pimpinan pada SMA di Kecamatan Dewantara hanya fokus pada penerapan konsep budaya organisasi sematamata tanpa ada upaya peningkatan kepuasan kerja guru maka budaya organisasi tidak akan berdampak terhadap peningkatan kinerja. Secara empirikal hasil penelitian ini sejalan dengan beberapa penelitian sebelumnya yang meneliti tentang pengaruh budaya organisasi terhadap kinerja melalui kepuasan kerja sebagai variabel intervening, misalnya penelitian Brahmasari \& Suprayetno (2008), Mariam (2016), Burhan, Pradhanawati \& Reni (2013), Novianti, Farida \& Widiartanto (2018), Baskoro, Hidayat \& Waluyo (2013) yang menemukan bahwa kepuasan kerja memediasi pengaruh budaya organisasi dan motivasi terhadap kinerja.

\section{PENGARUH GAYA KEPEMIMPINAN TERHADAP KINERJA MELALUI LINGKUNGAN KERJA}

Berdasarkan hasil perhitungan efek mediasi pengaruh gaya kepemimpinan terhadap kinerja guru melalui lingkungan kerja pada SMA Kecamatan Dewantara Kabupaten Aceh Utara, dapat dijelaskan bahwa lingkungan kerja memediasi secara penuh (full mediation) hubungan gaya kepemimpinan dengan kinerja guru SMA di Kecamatan Dewantara Kabupaten Aceh Utara. Hasil ini memberi makna bahwa gaya kepemimpinan akan berpengaruh secara signifikan terhadap kinerja guru SMA di Kecamatan Dewantara harus melalui upaya terciptanya lingkungan kerja yang kondusif sesuai dengan indikator lingkungan kerja yang diharapkan oleh para guru di SMA di Kecamatan Dewantara. Dengan kata lain bahwa pimpinan pada SMA di Kecamatan Dewantara harus fokus pada upaya menciptakan lingkungan kerja yang kondusif untuk meningkatkan peran atau fungsi budaya organisasi dalam meningkatkan kinerja guru SMA di lingkungan Kecamatan Dewantara Aceh Utara. Kajian empirikal dalam bidang ini berdasarkan penelusuran karya ilmiah baik secara online maupun secara ofline (bahan bercetak) yang dilakukan oleh peneliti tidak ditemukan adanya artikel atau jurnal yang menempatkan lingkungan kerja sebagai variabel mediasi antara gaya kepemimpinan dan budaya organisasi terhadap kinerja pegawai atau guru. Oleh karena itu penulis tidak dapat membandingkan hasil penelitian ini dengan penelitian lainnya. Namun demikian penelitian ini diharapkan menjadi sesuatu yang baru dalam model efek mediasi dan menjadikan manfaat dalam menambah referensi ilmiah dalam bidang terkait. 


\section{PENGARUH GAYA KEPEMIMPINAN TERHADAP KINERJA GURU MELALUI KEPUASAN KERJA}

Berdasarkan hasil perhitungan efek mediasi pengaruh gaya kepemimpinan terhadap kinerja guru melalui kepuasan kerja dapat dijelaskan bahwa kepuasan kerja memediasi secara penuh (full mediation) hubungan gaya kepemimpinan dengan kinerja guru SMA di Kecamatan Dewantara Kabupaten Aceh Utara. Secara empirikal hasil penelitian ini sejalan dengan beberapa penelitian sebelumnya yang meneliti tentang pengaruh gaya kepemimpinan terhadap kinerja melalui kepuasan kerja, misalnya penelitian Suyuthi dan Payangan (2009), Mariam (2009), Dhermawan, Adnyana dan Mudiartha. (2012), Pratiwi dan Yunina. (2011), Nurwijayanti, Hamzah, \& Nurjannah (2018), menemukan bahwa kepuasan kerja memediasi pengaruh gaya kepemimpinan dan lingkungan kerja terhadap kinerja pegawai.

\section{KESIMPULAN}

Berdasarkan hasil penelitian seperti yang telah dijelaskan pada bagian pembahasan, maka dapat dirumuskan beberapa kesimpulan sebagai berikut:

1. Budaya organisasi berpengaruh positif dan signifikan terhadap lingkungan kerja.

2. Gaya kepemimpinan berpengaruh positif dan signifikan terhadap lingkungan kerja.

3. Budaya organisasi berpengaruh positif dan signifikan terhadap kepuasan kerja.

4. Gaya kepemimpinan berpengaruh positif dan signifikan terhadap kepuasan kerja.

5. Budaya organisasi berpengaruh positif dan signifikan terhadap kinerja guru.

6. Gaya kepemimpinan berpengaruh positif dan signifikan terhadap kinerja guru.

7. Lingkungan kerja berpengaruh positif dan signifikan terhadap kinerja guru.

8. Kepuasan kerja berpengaruh positif dan signifikan terhadap kinerja guru.

9. Lingkungan kerja berpengaruh positif dan signifikan terhadap kepuasan kerja guru.

10. Kepuasan kerja memediasi secara penuh (full mediation) hubungan gaya kepemimpinan dengan kinerja guru.

11. Kepuasan kerja memediasi secara penuh (full mediation) hubungan budaya organisasi dengan kinerja guru.

12. Lingkungan kerja memediasi secara penuh (full mediation) hubungan gaya kepemimpinan dengan kinerja guru.

13. Kepuasan kerja memediasi secara penuh (full mediation) hubungan gaya kepemimpinan dengan kinerja guru.

\section{SARAN}

Berdasarkan kesimpulan penelitian seperti yang telah diuraikan di atas, maka dapat diberikan beberapa saran sebagai berikut:

1. Dalam rangka meningkatkan kepuasan kerja dan kinerja guru maka diharapkan kepada pimpinan atau kepala sekolah di Kecamatan Dewantara Kabupaten Aceh Utara untuk menjalankan gaya kepemimpinan yang baik misalnya pimpinan harus mampu memberikan dorongan kerja kepada bawahannya, menggunakan pola komunikasi yang baik dan efektif. Menggerakkan karyawan untuk melaksanakan standart kerja yang telah ditetapkan. Membangun hubungan kerja yang baik dan pimpinan harus mengutamakan kepentingan 
organisasi dalam bekerja. Di samping itu pimpinan juga harus berupaya mengawal terlaksananya budaya organisasi yang dapat meningkatkan keyakinan, norma-norma, dan nilainilai bersama yang menjadi karakteristik inti tentang bagaimana cara melakukan sesuatu di lingkungan sekolah.

2. Dalam upaya melembagakan budaya organisasi di sekolah diharapkan kepada Kepala sekolah di SMA Kecamatan Dewantara untuk mampu meningkatkan dan memperjelas norma-norma budaya di sekolah yang berorientasi pada guru dan karyawan.

3. Diharapkan kepada Kepala Sekolah agar lebih meningkatkan kemampuan menjadi perantara dalam menyampaikan informasi untuk memberitahu para guru apa yang harus dikerjakan. Di samping itu Kepala Sekolah juga harus meningkatkan kemampuan memberikan ide-ide kepada para guru dalam melaksanakan proses belajar mengajar. Kepala Sekolah diharapkan juga mampu berpartisipasi dan bekerjasama dengan baik dengan para guru. Kepala Sekolah juga diharapkan mampu mendelegasikan tugas kepada para guru dengan baik dan jelas.

4. Hasil analisis menunjukkan bahwa para guru merasa suasana kerja di lingkungan sekolah belum tercipta dengan kondusif dan hormoni oleh karena itu diharapkan kepada kepala sekolah agar mampu menciptakan suasana kerja yang baik di lingkungan sekolah.

\section{DAFTAR REFERENSI}

Agustiningrum, Andri. (2012). Gaya kepemimpinan dan motivasi kerja terhadap kinerja pegawai. Jurnal Prodi Ekonomi BKK Administrasi Perkantoran, FKIP Universitas Sebelas Maret.

Akhmad, Sudrajat. (2010). Manfaat prinsip dan asas pengembangan budaya sekolah. [On Line]. Tersedia :http://akhmadsudrajat.wordpress.com/ 2010/03/04/manfaat-prinsip-dan-asas-pengembanganbudaya-sekolah/ [06 Oktober 2010].

Andre., Sjovold., Rannestad., \& Rigdal. (2014). Influeance of organizational culture on working environment for employees and in healtcare oraganizations.

Anggraeni, Yenny., \& Santosa, T. Elisabeth Cintya. (2013).Pengaruh kepemimpinan transformasional terhadap kepuasan kerja karyawan. Jurnal Dinamika Ekonomi \& Bisnis 52 Vol. 10 No. 1 Maret 2013.

Arep, Ishak \& Tanjung, Hendrik. (2002). Manajemen Sumber Daya Manusia. Penerbit Universitas Trisakti. Jakarta.

Arifin, Noor. (2012). Analisis kualitas kehidupan kerja, kinerja, dan kepuasan kerja pada cv. duta senenan jepara. Jurnal Economia, Volume 8, Nomor 1, April 2012.

As'ad. Moh.(2003). Sumber Daya Manusia, edisi keempat, Liberty, Yokyakara.

Azwar, S. (2012). Metode Penelitian. Yogyakarta : Pustaka Pelajar.

Baron, R. M., \& Kenny, D. A. (1986). The moderator-mediator variable distinction in social psychological research: Conceptual, strategic, and statistical considerations. Journal of Personality and Social Psychology, 51, 1173-1182.

Baskoro, Bramastya Soeryo., Hidayat, Wahyu \& Waluyo, Handoyo Djoko. (2013). Pengaruh budaya organisasi, motivasi melalui kepuasan kerja terhadap kinerja karyawan pada PT. Janur Kuning Kudus. Jurnal Ilmu Administrasi Bisnis. Volume 2, Nomor 3, Tahun 2013. 
Bastian, Indra. (2014). Audit Sektor Publik: Pemeriksaan Pertanggungjawaban Pemerintahan. Edisi ke-3. Salemba Empat, Jakarta.

Bernardin, H. Jhon (2007). Human Resources Management. Mc. Graw Hill, Inc, Singapore.

Brahmasari, Ida Ayu., \& Suprayetno, Agus. (2008). Pengaruh motivasi kerja, kepemimpinan dan budaya organisasi terhadap kepuasan kerja karyawan serta dampaknya pada kinerja perusahaan (studi kasus pada PT. Pei Hai International Wiratama Indonesia). Jurnal Manajemen Dan Kewirausahaan, Vol.10, No. 2, September 2008: 124-135.

Burhan, Arif., Pradhanawati, Ari., \& Reni, S. Dewi. (2013). Pengaruh budaya organisasi dan komitmen organisasi terhadap kinerja karyawan dengan mediasi kepuasan kerja pada PT. BPR Setia Kabib Abadi Semarang. Journal of Social and Politik. Tahun 2013. Hal. 1- 9.

Danthi, Ni Made Ari. (2017). Pengaruh gaya kepemimpinan terhadap lingkungan kerja, motivasi kerja dan kinerja Pegawai Negeri Sipil pada Badan Pemberdayaan Perempuan dan Perlindungan Anak Provinsi Bali. Journal Ekonomi dan Bisnis, Vol.4, No. 1. Maret 2017. Hal 83-94.

Darmawan, Arif dan Putri, Marlinda Aulia. (2017). Pengaruh Gaya Kepemimpinan terhadap Komitmen Organisasi Melalui Kepuasan Kerja Sebagai Variabel Intervening. Akuntabilitas: Jurnal Ilmu Akuntansi Volume 10 (1), April 2017 P-ISSN: 1979-858X; E-ISSN: 2461-1190 Page 1 - 18.

Dewi Suryani, Bodiono. (2016). Pengaruh budaya Organisasi Terhadap Kinerja Karyawan Melalui Komitmen Organisasi sebagai Variabel Intervening Pada PT. Kerta Rajasa Raya. Jurnal Riset Ekonomi dan Manajemen Universitas Negeri Surabaya, Vol 16, No 1 Januari-Juni, Halaman 29-43.

Dhermawan, Anak Agung Ngurah Bagus. Sudibya, I Gde Adnyana \& Utama, I Wayan Mudiartha. (2012).

Pengaruh Motivasi, Lingkungan Kerja, Kompetensi, dan Gaya kepemimpinan Terhadap Kepuasan Kerja dan Kinerja Pegawai di Lingkungan Kantor Dinas Pekerjaan Umum Provinsi Bali. Jurnal Manajemen, Strategi Bisnis, dan Kewirausahaan Vol. 6, 173 No. 2 Agustus 2012.

Eliyanto. (2018). Pengaruh motivasi kerja dan lingkungan kerja terhadap kinerja guru SMA Muhammadiyah di Kabupaten Kebumen. Jurnal Pendidikan Madrasah, Volume 3, Nomor 1, PISSN: 2527-4287 - E-ISSN: 2527-6794.

Ferdinand, Augusty. (2006). Structural Equation Modelling dalam Penelitian Manajemen, Aplikasi Model-model Rumit Penelitian untuk Tesis Magister dan Disertasi Doktor, Fakultas Ekonomi, UNDIP.

Ghozali, Imam. (2013). Konsep dan Aplikasi Dengan Progran AMOS 21.0, Cetakan ke 4, Badan Penerbit Universitas Diponegoro, Semarang.

Gibson, James L., Jhon M. Ivancevich \& James H. Donnelly Jr. (2000). Organizations. MecGraw-Hill International, Boston.

Hair, J. F. JR., et al. (2009). Multivariate Data Analysis. Seventh Edition. Uper Sadle River. New Jersey. PrenticeHall.

Hakim, Adnan.(215). Effect of Organizational Culture, Organizational Commitment to Perfomance. The International Journal of Engineering and sciences Vol 4(5): 38-40. 
Hariandja, Marihot Tua Efendi. (2005). Manajemen Sumber Daya Manusia: Pengadaan, Pengembangan, Penggaya kepemimpinanan dan Peningkatan Produktivitas Pegawai. Jakarta: Grasindo.

Hasibuan, Malayu, SP. (2005). Manajemen Sumber Daya Manusia. Edisi Revisi. Bumi Aksara. Jakarta.

Heriyanti, Dewita. (2007). Analisis Pengaruh Budaya Organisasi, Kepuasan Kerja, Dan Gaya Kepemimpinan Terhadap Kinerja Karyawan Dengan Komitmen Organisasional Sebagai Variabel Interverning (Studi PT. PLN (Persero) APJ Semarang). Tesis. Program Studi Magister Manajemen. Program Pasca Sarjana Universitas Diponegoro.

Kartono, Kartini. (2011). Pemimpin dan Kepemimpinan, Jakarta PT. Rajawaligrafindo Persada Khanifah, Siti Palupiningdyah. (2015) Pengaruh kecerdasan emosional dan Budaya Organisasi pada Kinerja dengan Komitmen Organisasi. Manajemen Analysis Journal Vol 4(3) hal. 203210.

Kilapong, Samuel Novian. (2013). Kepemimpinan Transformasional, Self-efficacy, Self-esteem Pengaruhnya Terhadap Kepuasan Kerja Karyawan PT. Tropica Cocoprima Manado. Jurnal EMBA 141 Vol.1 No.4 Desember 2013, Hal. 141-150. ISSN 2303-1174.

Kosasih, Niki. (2014) . Analisis Pengaruh Budaya Organisasi dan Komitmen Keorganisasian terhadap Kinerja Pegawai. Jurnal Dinamika Manajemen Vol. 2(3): hal.199.

Kreitner, Robert \& Kinicki, Angelo. (2004). Organizational Behavior. $6^{\text {th }}$ edition. McGraw Hill.

Kreitner, Robert dan Kinicki, Angelo. (2005). Perilaku Organisasi. Salemba Empat: Jakarta.

Kusworo, Armanu, Rahayu, Minarti, Sumiati. (2015). Influence of Motivation, Organiational Kultur and Working Environment With Organizational Commitment as Mediator to Educator Perfomance. The International Journal of Social Sciences Vol 35(1): hal.6-10.

Lipu, Andi Tonra. Alam, Syamsu \& Umar, Fauziah. (2013). Kepuasan Kerja, Dukungan Organisasi, Gaya Kepemimpinan, Motivasi Kerja Terhadap Kinerja Karyawan pada PT. Bank Mega. Program Magister Manajemen Fakultas Ekonomi Universitas Hasanuddin.

Luthans, F. (2006). Perilaku Organisasi. Yogyakarta: Penerbit Andi.

Mahmudi. (2005). Manajemen Kinerja Sektor Publik. Yogyakarta: UPP AMP YKPN.

Mangkunegara, Anwar Prabu. (2008). Manajemen Sumber Daya Manusia Perusahaan. PT Remaja Rosdakarya. Bandung.

Mariam, Rani. (2016). Pengaruh gaya kepemimpinan dan budaya organisasi terhadap kinerja melalui kepuasan kerja karyawan sebagai variabel intervening pada Kantor Pusat PT. Asuransi Jasa Indonesia (Persero). Journal Online.

Mas'ud, Fuad. (2004). Survai Diagnosis Organisasional (Konsep dan Aplikasi), Badan Penerbit Universitas Diponegoro.

Mathis, Robert L. \& Jackson, John H. (2001). Human Resource Management (Terjemahan). Buku 1. Edisi Kesembilan, Penerbit Salemba Empat. Jakarta.

Mila, Yumaroh., \& Lili, Andriani. (2017). Pengaruh lingkungan kerja terhadap kinerja guru di SMK Negeri 10 Kecamatan Sungai Gelam Kabupaten Muaro Jambi. Scientific Journals of Economic Education, Vol. 1, No. 1. 
Nafisah, Durrotun. (2005). Analisis Pengaruh Gaya Kepemimpinan Terhadap Kepuasan Kerja, Komitmen Organisasi dan Kinerja Karyawan. Fakultas Ekonomi. Universitas Diponegoro.

Norlina, M. Ali., Rohani, Jangga., Mazlina, Ismail., \& Muhammad, Nazri, Ali. (2015). Influence of leadership styles in creating quality work culture. Procedia Economics and Finance.31 (2015) 161169.

Novianti, Nines Intan., Farida, Naili., \& Widiartanto. (2018). Pengaruh budaya organisasi dan motivasi kerja terhadap kinerja karyawan dengan kepuasan kerja sebaigai variabel intervening (Studi terhada karyawan PT. BPR. Artha Mukti Santosa Semarang). Dikutip pada laman www.media.neliti.com. Tanggal 28 Juni 2019.

Nurwijayanti., Djabir, Hamzah., \& Nurjannah, Hamid. (2018). Pengaruh gaya kepemimpinan dan lingkungan kerja terhadap kinerja karyawan melalui kepuasan kerja sebagai variabel intervening pada PT. Wedu Kabupaten Merauke. Hasanuddin Journal of Applied Business and Enterpreneurship, Vo. 2, No. 1.

Pancawati, Sri. (2013). Pengaruh Iklim Organisasi, Motivasi Dan Kompetensi Terhadap Kinerja Pegawai Bagian Pembangunan Pemerintah Kabupaten Kediri. Jurnal OTONOMI, Vol. 13, Nomor 1, Januari 2013.

Patulak, Martin Efendi. Thoyib, Armanu. Surachman Setiawan, Margono.(2014). The Role of Organizational Commitment as Mediator of Organizational Cultur and Employes Performance. Journal of Economics and Sustainable Devolopment Vol.4(5): hal 169-172.

Pratiwi, S. Yunina. (2011). Pengaruh gaya kepemimpinan dan lingkungan kerja terhadap kinerja karyawan melalui kepuasan kerja sebagai variabel intervening (Studi pada Perusahaan Daerah Air Minum Kabupaten Winosobo). Thesis Magister tidak dipublikasikan.

Prihayanto, Susandi \& Ratnawati, Intan. (2011). Analisis Pengaruh Budaya Organisasi dan Motivasi Terhadap Kinerja Karyawan (Studi pada PT. Telekomunikasi Indonesia Tbk, Regional IV Jawa Tengah-Daerah Istimewa Yogyakarta). Yogyakarta.

Putriana, Lies.(2015). The Infact of Organizational Cultur on Jon Satifaction, Organizational

Commitment And Job Perfomance. International Journal of Education and Research Vol 3(9) :hal. 108-109.

Riani, Asri Laksmi (2011). Budaya Organisasi .Yokyakarta : Graha Ilmu.

Rifa Elfita., Zulhaini., \& Ikrima, Mailani. (2019). Pengaruh lingkungan kerja terhadap kinerja guru pendidikan agama islam di MTS Negeri Sentajo Filial Singingi Kecamatan Singingi Kabupaten Kuantan Singingi. Jurnal Al-Hikmah, Vol. 1, No. 1.

Robbins, S.P. (2008). Perilaku Organisasi. Jakarta: PT Salemba Empat.

Robbins, Stephen P. \& Timothy A. Judge. (2009). Organizational Behavior. Thirteenth Edition. New Jersey: Pearson Prentice Hall.

Sedarmayanti. (2007). Sumber Daya Manusia dan Produktifitas kerja, Bandung, Penerbit Bandar Maju.

Setiawan, Edi dan Mardalis. (2015). Pengaruh Gaya Kepemimpinan dan Komitmen Organisasi Terhadap Disiplin Kerja dengan Kepuasan Kerja Sebagai Variabel Intervening. Daya Saing. Jurnal Ekonomi Manajemen Sumber Daya. Vol. 17, No. 2, Desember 2015. 
Shahzad, Fakhar Iqbal, Zahid Gulzar, Muhammad.(2013). Impact of Organizational Culture on

Employes Job Ferfomance. Journal F Business Studies Quarterly Vol 5(2): hal. 59-63.

Siagian, P, Sondang. (2007). Manajemen Sumber Daya Manusia. Jakarta: Bumi Aksara.

Silen, Adhi Prastistha. (2016). Pengaruh Kompetensi dan Pengembangan Karir Terhadap Kepuasan Kerja dengan Komitmen Organisasional Sebagai Variabel Mediasi (Studi Pegawai Politeknik Ilmu Pelayaran (PIP Semarang). Jurnal Bisnis dan Ekonomi (JBE), September 2016, Hal. 174 - 185 Vol. 23, No. 2 ISSN: 1412-3126.

Sopiah, (2008). Perilaku Organisasi. Edisi Pertama, Yokyakarta :ANDI

Sugiyono. (2011). Metode Penelitian Kuantitatif Kualitatif dan R \& H. Alfabeta. Bandung.

Sukarjati, Endang, et.al (2016). Pengaruh Kepemimpinan, Pengembangan Sumber daya Manusia dan Kepuasan Kerja Terhadap Kinerja Pegawai Kantor dinas Pengelolaan Keuangan dan asset daerah kota Semarang. Jurnal Managemen, Vol.02, Maret 2016, Universitas Pandanaran Semarang.

Sutrisno, Edy. (2011). Manajemen Sumber Daya Manusia. Jakarta: Kencana.

Taurisa, C.M., \& Ratnawati, I. (2012). Analisis Pengaruh Budaya Organisasi dan Kepuasan Kerja terhadap Komitmen Organisasional dalam Meningkatkan Kinerja Karyawan (Studi pada : PT. Sido Muncul Kaligawe Semarang, Jurnal Bisnis dan Ekonomi (JBE). 19 : 2 170-187.

Torang, Syamsir. (2012). Metode Riset Struktur \& Perilaku Organisasi. Alfabeta, Bandung.

Ulfa, H. Dienillah. (2018). Pengaruh lingkungan kerja terhadap kinerja guru pada SMK Muhammadiyah 1 Ciputat. Universitas Pamulang, Tangerang Selatan.

Valizadeh, Ali., \& Ghahremani, Jafar (2012). The relationship between organizational culture and quality of working life of employees. European Journal of Experimental Biology, 2012,2(5):1722-1727.

Wahyudi, Rizki., \& Nurjaman, Sidik. (2018). Pengaruh budaya organisasi dan lingkungan kerja terhadap kepuasan dan kinerja karyawan.

Wibowo. (2007). Manajemen Kinerja, PT. Raja Grafindo Persada, Jakarta.

Wibowo. (2013). Budaya Organisasi, PT. Raja Grafindo Persada, Jakarta

Wirawan. (2009). Evaluasi Kinerja Sumber Daya Manusia. Jakarta: Salemba Empat.

Yulk, Gary A.(1989)Manajerial Leadership . A Review of Theory and Research. Journal of Management, Vol ,15, No.2, 251-289 